\title{
Examining Child Development from an African Cultural Context
}

\author{
Winnie Mucherah ${ }^{1}$ and Teresia Mbogori²
}

\begin{abstract}
Human development is multifaceted and characterized by physical, cognitive, social and emotional aspects. This development is strongly shaped by one's socio-cultural context. It is impossible to separate one's culture when explaining their development fully. The purpose of this paper is to critically examine key issues in child development through the lens of an African context. These key issues include language development, child birth practices, self-esteem, self-concept and identity development. Language is a powerful tool of communication that consists of words used by a community. It enables us to pass down information from one generation to the next and creates a rich cultural heritage. For this reason, this paper examines the languages that are used in African schools and how they impact the development of an African child. Another important issue that needs to be examined within the African context is the birth process. Even though childbirth is considered a natural event, it takes place in different contexts and parents make important choices about conditions surrounding birth. The people who help a mother during birth vary across cultures and these childbirth settings and attendants impact the mother's experience, particularly with regards to how she will interact with her child after birth, which consequently influences child development. Finally, self-esteem, self-concept and identity development are strongly embedded in one's cultural context. A healthy self-esteem and positive self-concept impacts a strong identity development. To gain a better understanding of these key concepts within the African cultural context, the framework of Vygotsky's social-cultural theory will be utilized.
\end{abstract}

Keywords: Child development, African Culture, Self-esteem, Self-concept, Identity

\section{Introduction}

The development of a child is multifaceted and characterized by several dimensions including the physical, cognitive, social and emotional aspects. This development is strongly shaped by one's socio-cultural context. It is impossible to separate one's culture and context in fully explaining their development. For example, constructs like motivation for academic achievement, self-concept, self-esteem, and identity development can only be adequately understood within one's social-cultural contexts and values (Mahn \& John-Steiner, 2013). What motivates a student in Kenya to achieve academically may be totally different from what motivates a student in the United States to achieve (Mucherah, 2008; Mucherah \& Yoder, 2008).

Full listing of authors and contacts can be found at the end of this article.
Unfortunately, most frames of reference in explaining "optimal" development seem to be based on the Western and European standards (Schwartz et al, 2013). Almost all examples given in textbooks are Western and or European based, hardly any from an African perspective, unless it's explaining "inadequate" development. In addition, research given in support of discussions used to explain development in Africa or other developing countries tend to be conducted by Westerners, with few African first authors. Furthermore, majority of African scholars tend to interpret their research findings within the Western and or European framework. Clearly, there is a need to increase research productivity from Africa and by African scholars. It is paramount that the African scholars interpret their research findings through the African lens. The world is becoming a global village and Africa has to participate in this endeavor by 
actively participating in empirical-based research and share with the world the unique aspects its culture contribute to understanding children's development. Clearly, there is a need for transformation in the education system on the continent of Africa. The ideal place to start cultivating this transformation is through schools, starting from early childhood education. This paper will address five key aspects of child development that needs to be critically examined within the African context. They include language development, child birth approaches, self-esteem, self-concepts, and identity development. In addition, these conecpts will be examined within the framework of Vygotsky's socio-cultural theory.

\section{Social Cultural Theory}

The sociocultural theory, developed by Lev Vygotsky, posits that social interaction and culture plays an important role in children's construction of knowledge. According to this theory, culture and social interactions are indispensable to children's interpretations and understanding of cultural expectations (Bodrova \& Leong, 2007; Vygotsky, 1962). In Vygotsky's view, knowledge is distributed among people and the environments in which they live. These environments are embedded in the cultural contexts of family, school, media, legal and religious institutions, and community organizations. According to Vygotsky, children's social interaction with more skilled adults and peers is inseparable from their knowledge development. Through this interaction, they learn to use the tools that will help them adapt and be successful in their culture. For example, if you regularly interact with children in their native language, you not only advance their language skills but also communicate to them that their native language is an important aspect of their culture. Therefore, this theoretical approach suggests that the knowledge, perceptions, attitudes and beliefs about language, childbirth practices, beauty, self-concept and identity development among African children is advanced through interaction with others within the sociocultural contexts.

\section{Early Childhood and Language Development}

There is a need to engage teachers, scholars and policy makers in discussions on the cultural contexts influencing children's development. For example, an intentional examination of the early childhood curriculum is warranted. How are children introduced to formal education? What aspects in the curriculum promote the African culture? When teaching the alphabet, what examples are given to support each letter of the alphabet? For example, A is for... The colonial education used Western and/or European based examples such as A for Apple. Most children, particularly those in the rural areas have never seen an apple! Unfortunately, this is still being used in early childhood education in Kenya despite gaining independence in the early 60s. What languages are used for instruction in schools? An examination of the school systems in most African countries, particularly in Kenya, reveal foreign languages are the main languages of instruction. How many African languages are encouraged or simultaneously used with the foreign languages such as English or French?

In some countries, children are punished for using their native language at school, and this can have a negative effect on children if they become ashamed of their native language (Mucherah, 2008). Furthermore, punishing children for using their native language sends the message that their language is not important. This is unfortunate because children should be encouraged to maintain their native language while learning a second language as research shows children can pick up many languages simultaneously (Thomas \& Johnson, 2008). Furthermore, compared to adolescents and adults, children have the ability to pronounce words with a native-like accent in a second language if it is introduced early (Neville, 2006). Therefore, instead of punishing children for speaking their heritage language at school, teachers should be trained so that they can effectively use both/all languages for instruction. There is a need for more resources to be invested in training teachers to be culturally responsive in their instructional practices, and also to abolish practices such as humiliating or beating students who speak their native language in school. This is a problem because in some cases, parents tend to be happy when these children can not speak their native language. According to Ngugi Wa Thiong'o (1986) these parents may not realize it but they have been programed by the colonial mentality. Africans have to decolonize their mind in order to embrace their native languages (Thiong'o, 1986). Ngugi goes on to say that historically, English came to be seen automatically as the language of intelligence and African languages as peripheral. This was a conscious program enacted by all colonial powers. However, the colonial period is long gone and it is time for African education systems to re-examine their educational mission and practices. African have access to many languages and this is a signifcant resource because 
children who are fluent in two or more languages perform better than their single-language counterparts on tests of control of attention, concept formation, analytical reasoning , inhibition, cognitive flexibility, cognitive complexity, and cognitive monitoring (Bialystok, 2001, 2007, 2011; Bialystok \& Craik, 2010).

Ironically, in most cases children who speak more than one native language in Africa feel inferior to those who speak only one foreign language such as English or French. It would be in the interest of the children and the African culture in general, to promote and combine both the native and foreign languages for instruction at school. There is some hope in Kenya because the current curriculum is emphasizing the use of Kiswahili, which is the national language. In addition, the Ministry of Education in Kenya has reintroduced African languages which has promoted a publishing house like East African Educational Publishers to issue numerous books on how to learn different mother tongues in Kenya such as Dholuo, Ekegusii and Kiluhya (Ministry of Education, 2015). Despite this glimpse of hope, most Kenyans prefer their children to be fluent in English, even if it is at the expense of the national and heritage language (Mucherah, 2008). Kenji Hakuta $(2001,2005)$ support the combined heritage and foreign language approach because children have difficulty learning a subject when it is taught in a language they do not understand. Furthermore, when both languages are integrated in the classroom, children learn the foreign language more readily and participate more actively. of great significance, children recognize the value of their heritage language and embrace it with pride.

\section{Childbirth within the African Context}

Childbirth commences the process of child development. For centuries, the process of childbirth occurred in the homes. In the Kenyan culture, particularly the Luhya culture, there are women who help a mother during childbirth, they are referred to as birth attendants. These women are experts in customary midwifery and are known and respected in the community. This practice minimizes the stress of a pregnant woman since the midwife is usually familiar with the women whom she assists in the childbirth. Less stress during child birth promotes relaxation in the mother and enhances the childbirth experience. This positive experience enhances the parent-infant interaction after birth, which increases positive social and emotional development of both mother and infant (Kennell, 2006). However, this trend is gradually changing and children are being delivered at the hospital by nurses and doctors. This is all good, if this is done for the sole purpose of hygiene, minimizing infections, and for the purpose of safety of the infant and the mother. Unfortunately, home deliveries are now frowned upon while hospital births are viewed as progressive because in the Western world like the United States, 99\% of births take place in the hospital (Martin et al, 2005). The problem is, not every family in Africa can afford the hospital bill nor the means to get to the hospital in time for a safe delivery. It would therefore be helpful for the traditional mid-wives to work alongside a trained nurse and doctor so that emergences are taken care of if they happen, and the traditional mid-wifery expertise is preserved.

Not surprisingly, and fortunately, in most African cultures, midwives or women who help with child birth are very common and research shows for lowrisk women, midwife-led delivery is characterized by a reduction in procedures during labor and increased satisfaction with care (Sutcliffe et al, 2012). This is not unique to Africa because midwifery is practiced in most countries throughout the world (Jesse \& Kilpatrick, 2013). This is important because mid-wives are usually community members who can eaily be sort for advice after the baby is born, unlike the hospital birth where the nurses and/or doctors are not easily accessable. In addition, the mid-wives speak the same language as the new mother, therefore, communication is easy and cultural expertise on how to care for the newborn is shared. This is important because this communication of what to do after the baby is born helps the mother to relax and bond with her baby. In some cases, hospital deliveries can be cold and distant especially for mothers from rural and low income families. Sometimes, the language used by doctors is not understood by the mother, which can make the mother feel inept as a parent. Feelings of incompetence can affect parent-infant interacrion after birth. Physicians believe that during the period shortly after birth, the parents and newborn need to form an emotional attachment as a foundation for optimal development in the years to come (Kennell, 2006). In some mother-infant-pairs, including preterm infants and mothers from disadvantaged circumstances, early bonding may establish a climate for improved interaction which promotes optimal child development (Kennell, 2006). It would therefore be beneficial for the medical profession to tap into this expertise by working together with the midwives to reduce the stigma attached to home births and promote safe births for 
low-income mothers. This will also preserve the natural and African cultural funds of knowledge. This expertise has been passed on from generation to generation and if the current hospital deliveries continue, Africa will lose this valuable skill. According to the socio-cultural theory, knowledge is learned and shared through social interaction and engagement in culturally valued activities. Therefore, trained medical professionals working alongside traditional mid-wives sends the message that this is a valued expertise in the African culture.

\section{Self-esteem and Self-concept}

Another key concept in children's development is self-understanding which includes self-esteem, self-concept and identity. Children's conceptions and understanding of self is their cognitive representation and is the central aspect of their personality and psychological well-being (Harter, 2012; Rochat, 2013). A child's self-understanding is based, in part, on the various roles and membership categories that define who children are, and more importantly, it is deeply embedded in their social-cultural contexts (Harter, 2006; 2012). The large question here is, how do African children define themselves? What attributes are central to their self-understanding? A healthy understanding of Self promotes one's self-esteem, which is associated with positive life outcomes (Harter, 2012). Self-esteem refers to a person's self-worth or self-image, while self- concept refers to a domain-specific evaluations of self (Harter, 2012). Having a high self-esteem and a positive self-concept are important aspects of children's well-being (Baumeister, 2013; Campbell, 2012). For years, beauty has been defined based on the Western and/or European standards. For example, long, straight hair and fair skin for women have been the criteria for judging women's beauty (Mucherah \& Frazier, 2013). Rarely are African attributes embraced in the definition of beauty. In the 60's there was a movement in the United States of America, championed by prominent African Americans like James Brown, to promote Black Beauty. This movement promoted wearing natural hair, Afro, and encouraged Black people to embrace darker skin tones. Unfortunately, this movement faded in the 80's and the 90's, but emerged again in the Twenty-first century. There is also hope because in the United States prominent people and celebrities in Hollywood are now wearing natural hair and embracing African names. If self-esteem refers to a person's self-worth or self-image, and if Western or European standards are used to determine one's perceptions of beauty, this is bound to be problematic for African children. Since the era of Clark and Clark's Doll study which found that African American children preferred lighter skin tone dolls, scholars have grappled with the issue of beauty and skin tone (Mucherah \& Frazier, 2013). Mucherah and Frazier's study (2013) found that majority of women of African descent preferred lighter skin tone and this was significantly correlated with their self-esteem. Findings like this present a challenge to Africans who are trying to instill a sense of pride in African children with darker skin tones. Research indicates that variations in self-esteem have been linked with many children's development. For example, children with high self-esteem show greater initiative. They are also prone to prosocial behavior and exhibit more happiness (Baumeister \& others, 2003. On the contrary, studies show that individuals with low self-esteem report more feelings of depression and have lower levels of life satisfaction (Birkeland et al, 2012).

\section{Possible Ways to Raise Children's Self-esteem with- in the African Context}

The findings from reviewed studies affirm the importance of increasing children's self-esteem within the African cultural context (Baumeister, 2013; Campbell, 2012; Harter, 2012; Mucherah \& Frazier, 2013; Rochat, 2013). This process starts with the educators, guardians and any adult who serves as a role model, that they need to embrace and promote African attributes, values and norms with conviction. One way to raise children's self-esteem is by providing emotional support and social approval (Harter, 1999). Emotional support and social approval can be powerful influences on children's self-esteem. The support and approval can be from teachers, parents and peers through encouragement and praise when children embrace culturally relevant behaviors and activities. For example, wearing cultural dresses/outfits, natural hair/braids, eating and enjoying traditional African foods, and speaking their heritage languages. Some of the current trends on the content are promising. For instance, it's encouraging to see young women and men embrace African attributes such as natural hair/braids and dark skin tone, use of African names only, and use of native languages with pride. This is important because our efforts to understand ourselves and to develop an identity that reflects our cultural heritage is long overdue. However, there is more that can be done to promote children's self-esteem in schools. For example, there is a need to re-examine the textbooks that are used in schools. Who are 
the authors? Having many books with African authors is a place to start. Even better, having books that are written in African languages would greatly promote African languages and pride in the African culture. Finally, having books with main characters who are African helps children to see "themselves" in these books and sends a message that African characters are important.

\section{Identity Development}

Children start to grapple with identity in middle childhood. They start to have questions such as "Who am I?" "What do I want to be when I grow up?" As they look for answers to these questions, they are paying close attention to their social contexts such as home, neighborhood, school, and community at large. The process of identity development helps children to navigate some of the challenging and awkward social issues as they interact with their peers. This is critical because identity is who a person is and represents a synthesis and integration of self-understanding (Erikson, 1968). Vygotsky would argue that a child's identity development is significantly influenced by the social cultural contexts including the interactions with more knowledgeable members of society (Vygotsky, 1962). According to Erikson, identity is a self-portrait composed of many pieces including the career a person wants to pursue, country of origin and how intensely the person identifies with his or her cultural heritage, and the kind of things a person likes to do which include sports, music, hobbies and interests (Erikson, 1968; Moshman, 2011). Africa is known for its immense wealth in music, folk songs and dances. These folk songs should not only be performed during special occasions like school and college competitions. Rather, they should be woven into the daily lives of Africans so that children grow-up embracing these African gems. The challenge is, how strongly do African children embrace their African identity with its attributes? The world is becoming small and Africa needs to be represented in this "small" world. As Vygotsky's socio-cultural theory posits, the social contexts play significant roles in identity. For example, family, culture, and ethnicity are linked to identity development. Unfortunately, most research on identity development has been based on data collected from adolescents and young adults in the United States and Canada (Schwartz et al, 2013). Many of these individuals have grown up with a cultural identity that emphasizes the individual. However, in many countries around the world, adolescents and young adults have grown up influenced by a collectivist emphasis on fitting in with the group and connecting with others. The collectivist emphasis is especially prevalent in African countries such as Kenya. Research has found that African adolescents and young adults develop their identity through identification with and imitation of others in the cultural group (Bosma \& Kunnen, 2001). This emphasis on interdependence in African cultures includes an expectation that adolescents and young adults will accept and embrace social and family roles (Berman et al, 2011). Ethnic identity is an enduring aspect of the self that includes a sense of membership in an ethnic group, along with the attitudes and feelings related to that membership (Phinney, 2006).

Identity development becomes a central feature during adolescence. Most young people start to grapple with issues such as "What is my purpose in life?" (Erikson, 1968). Helping African youth navigate the challenges of their ethnic identity by providing opportunities for them to experience strong African values and attributes with pride, is critical. This is because research shows that a positive ethnic identity is related to positive outcomes for ethnic minority adolescents (Umana Taylor et al, 2012). Furthermore, adolescents' positive ethnic identity is linked to higher self-esteem, school connectedness, and a healthy social functioning (Jones \& Galliher, 2007). It is therefore safe to state that it's imperative to ensure that African adolescents develop a positive ethnic identity as Africans.

\section{Conclusion}

A comprehensive understanding of factors that impact the major aspects of child development requires an awareness of the relevant cultural contexts. This understanding begins with institutions of education that promote the values and practices embedded in the African cultural heritage. Educators and policy makers need to start re-examining their curriculum and teacher practices. In addition, scholars need to develop research instruments that are culturally relevant and to intentionally assess the construct validity of the research instruments in order to adapt the current Western and European measures to the African context. One of the challenges facing transformative education is that there are not many writers in African languages on the continent. The continent appears to be captive to European languages and hostile towards African languages. According to Ngugi, Africa has to make an intentional effort to change because losing a language is losing one's soul 
(Thiong'o, 1986). There is clearly a need in Africa to adopt a three-language policy where, in the case of Kenya for example, every child will be grounded in their mother tongue, Kiswahili and then English. The environments in which children in Africa develop should exposure them to strengths and values of the continent. For example, schools should teach the Egyptian civilization, before Western and Greek history. Egyptian civilization is the missing link in most of the African education system, yet the 3,000 years of Egyptian civilization showed that they did incredible things (Thiong'o, 1986). These Egyptian inventors were Black Africans who were leaders in art, sculpture, and astronomy. They also invented writing (Hieroglyphs)! As children in Africa develop, they need to have this knowledge. This goes back to the African native languages, authors, writers, and books because the lack of confidence in ourselves begins with hating our native languages. The history carried by those languages is erased, there is no memory of Africa inventing things when we abandon our native languages (Mucherah, 2008).

This is supported by Vygotsky's theory of socio-cultural development. Culture and social interactions guide children's development. Child development is inseparable from cultural and social activities. The education system in Africa needs to provide relevant competencies for their children, embedded within the cultural contexts, so that they emerge from these institutions and stand on the world stage with pride for their African culture and without an excuse!

\section{References}

Baumeister, R. F. (2013). Self-esteem. In E. Anderson (Ed.), Psychology of classroom learning: An encyclopedia. Detroit: Macmillan.

Baumeister, R. F., Campbell, J. D., Krueger, J. I., \& Vohs, K. D. (2003). Does high self-esteem cause better performance, interpersonal success, happiness, or healthier lifestyles? Psychological Science in the Public Interest, 4(1), 1-44.
Berman, S. L., You, Y. F., Schwartz, S., Teo, G., \& Mochizuki, K. (2011, February). Identity exploration, commitment, and distress: A cross national investigation in China, Taiwan, Japan, and the United States. In Child \& Youth Care Forum (Vol. 40, No. 1, pp. 65-75). Springer US.

Bialystok, E. (2001). Bilingualism in development: Language, literacy, and cognition. Cambridge University Press.

Bialystok, E. (2007). Acquisition of literacy in bilingual children: A framework for research. Language Learning, 57, 45-77.

Bialystok, E. (2011). Becoming bilingual: Emergence of cognitive outcomes of bilingualism in immersion education. Paper presented at the meeting of the Society for Research in Child Development, Montreal.

Bialystok, E., \& Craik, F. I. (2010). Cognitive and linguistic processing in the bilingual mind. Current Directions in Psychological Science, 19(1), 19-23.

Birkeland, M. S., Melkevik, O., Holsen, I., \& Wold, B. (2012). Trajectories of global self-esteem development during adolescence. Journal of Adolescence, 35(1), 43-54.

Bodrova, E., \& Leong, D.J. (2007). Tools of the mind: The Vygotskian approach to early childhood education (2nd ed). Upper Saddle River, NJ: Merrill/Prentice Hall.

Bosma, H. A., \& Kunnen, E. S. (2001). Determinants and mechanisms in ego identity development: A review and synthesis. Developmental Review, 21(1), 39-66.

Campbell, J. D. (1990). Self-esteem and clarity of the self-concept. Journal of Personality and Social Psychology, 59(3), 538.

Erik, E. (1968). Identity: Youth and crisis. New York. W. W. Norton.

Hakuta, K. (2001, April 5). Key policy milestones and directions in the education of English language learners. Paper prepared for the Rockefeller Foundation Symposium, Leveraging change: An emerging framework for educational equity, Washington, DC.

Hakuta, K. (2005, April). How long does it take English learners to attain proficiency? Berkeley, CA: The University of California Linguistic Minority Research Institute Policy Report 2000-1.

Harter, S. (1999). The construction of the self. New York: Guilford. 
Harter, S. (2006). The self. In W. Damon \& R. Lerner (Eds.), Handbook of Child Psychology (6th ed.), New York: Wiley.

Harter, S. (2012) The construction of the self (2nd ed.). New York: Wiley.

Jesse, D. E., \& Kirkpatrick, M. K. (2013). Catching the spirit of cultural care: a midwifery exemplar. Journal of Midwifery \& Women's Health, 58(1), 49-56.

Jones, M. D., \& Galliher, R. V. (2007). Ethnic identity and psychosocial functioning in Navajo adolescents. Journal of Research on Adolescence, 17(4), 683-696.

Kennell, J.H. (2006). Randomized controlled trial of skin-to-skin contact from birth versus conventional incubator for physiological stabilization in $1200 \mathrm{~g}$ to 2199 g newborns . Acta Paediatrica (Sweden), 95, 15-16.

Mahn, H., \& John-Steiner, V. (2012). Vygotsky and sociocultural approaches to teaching and learning. In I. B. Weiner \& others (Eds.), Handbook of Psychology, (2nd ed., Vol. 7). New York: Wiley.

Martin, J. A., Hamilton, B. E., Menacker, F., Sutton, P. D., \& Matthews, T. J. (2005, November 15). Preliminary births for 2004: Infant and maternal health. Health E-Stats. Atlanta: National Center for Health Statistics.

Ministry of Education, Science and Technology (2015). National Curriculum Policy.

Moshman, D. (2011). Adolescent rationality and development: Cognition, morality, and identity (3rd ed.). New York: Psychology Press.

Mucherah, W. \& Frazier, D. (2013). How deep is skin deep? The effects of skin color and self-esteem on estimations of body image among women of African decent. Journal of Applied Social Psychology, 43(6), 1177-1184.

Mucherah, W. (2008). Classroom climate and students' goal structures in high school niology classrooms in Kenya. Learning Environments Research: An International Journal, 11, 63-81.

Mucherah, W. \& Yoder, A. (2008). Motivation for reading and niddle school students' performance on standardized testing. Reading Psychology: An International Journal, 29, 214-235.

Mucherah, W. (2008). Immigrants' perceptions of their native language: Challenges to actual use and maintenance. Journal of Language, Identity, and Education, 7, 188-205.
Neville, H. J. (2006). Different profiles of plasticity within human cognition. In Y. Munakata \& M. H. Joshnson (Eds.), Attention and Performance XXI: Processes of change in brain and cognitive development. Oxford, UK: Oxford University Press, 287-314.

Phinney, J. S. (2006). Ethnic identity exploration in emerging adulthood. In J. J. Arnett \& J. L. Tanner (Eds.), Emerging adults in America. Washington, DC: American Psychological Association.

Rochat, P. (2013). Self-conceptualizing in development. In P. D. Zelazo (Ed.), Oxford handbook of developmental psychology, (Vol. 2). New York: Oxford University Press.

Schwartz, S. J., Donnellan, M. B., Ravert, R. D., Luyckx, K., \& Zamboanga, B. L. (2012). Identity development, personality, and well-being in adolescence and emerging adulthood: Theory, research, and recent advances. In I. B. Weiner \& others (Eds.), Handbook of Psychology, (2nd ed., Vol. 7). New York: Wiley.

Sutcliffe, K., Caird, J., Kavanagh, J., Rees, R., Oliver, K., Dickson, K., ... \& Thomas, J. (2012). Comparing midwife-led and doctor-led maternity care: a systematic review of reviews. Journal of Advanced Nursing, 68(11), 2376-2386.

Thomas, M. S., \& Johnson, M. H. (2008). New advances in understanding sensitive periods in brain development. Current Directions in Psychological Science, 17(1), 1-5.

Thiong'o, N. (1986). Decolonizing the Mind: The Politics of Language in African Literature. James Currey Publishers, New York, NY.

Umaña-Taylor, A. J., Wong, J. J., Gonzales, N. A., \& Dumka, L. E. (2012). Ethnic identity and gender as moderators of the association between discrimination and academic adjustment among Mexican-origin adolescents. Journal of Adolescence, 35(4), 773-786.

Vygotsky, L.S. (1962). Thought and language. Cambridge, MA: MIT Press.

\section{Authors}

${ }^{1}$ Winnie Mucherah (wmucherah@bsu.edu) is Professor in the Department of Educational Psychology at Ball State University, Muncie, Indiana, USA.

2 Teresia Mbogori (tnmbogori@bsu.edu) is an Assistant Professor in the Department of Nutrition and Health Physiology at Ball State University, Muncie, Indiana, USA. 